\title{
FIRST NATURAL TRANSVERSE FREQUENCY OF TRUNCATED CONE AND WEDGE BEAMS
}

\author{
Vazgen Bagdasaryan, Marek Chalecki, Michał Gierasimiuk, Jacek Jaworski, \\ Olga Szlachetka ${ }^{凶}$
}

Faculty of Civil and Environmental Engineering, Warsaw University of Life Sciences - SGGW, Warsaw

\begin{abstract}
Using the Rayleigh's method, the first natural frequency and period corresponding to the first mode of transversal vibrations for cone and wedge beams, having non-uniform cross-section, are calculated in this study. Six different supporting schemes are considered. It has been assumed that the beams are made of a homogeneous and elastic material and the deflection line of the beam axis during vibrations has the same shape as the axis deflected by a static constant uniform continuous load. The values of frequencies, calculated according to the presented procedure, have been compared to the results obtained in the Finite Element Method as well as to the benchmark solutions given in the literature for the natural vibrations of Euler-Bernoulli's beam. High conformity of results, enough for engineering calculations, is concluded.
\end{abstract}

Key words: truncated cone beam, truncated wedge beam, first natural frequency, Rayleigh's method

\section{INTRODUCTION}

One of the methods of calculation of frequencies of subsequent modes of free vibrations is the integration - for definite boundary conditions - of the differential equation of Euler-Bernoulli beam. A procedure enabling to achieve solution in form of Bessel functions and then numerical solution for truncated cone and truncated wedge beam is presented by Conway and Dubil (1965). Other authors submitted solutions to calculate natural frequencies for beams having variable crosssections and various shapes: for example in the case of beams having constant size in one direction (e.g. width) and variable in second direction - linearly (Datta \& Sil, 1996), parabolically (Caruntu, 2009), exponentially (Ece, Aydogdu \& Taskin, 2007) - or for double tapered beams (Zhou \& Cheng, 2000). Moreover, studies have been undertaken on vibrations of such variable cross-section beams as for example: with concentrated masses (Wu \& Chiang, 2004; Torabi, Afshari \& Najafi, 2013), consisting of two segments (Laura, Gutierrez \& Rossi, 1996) or considering other dynamic effects (Wang, 2012). For many cases, as beams in form of hollow solids of revolution (curvilinear truncated cones with generatrices described by some selected curves), there are no benchmark solutions in the literature. In this case, the Rayleigh's method is useful which allows to determine the first natural frequency of such beams. This approach was applied by Jaworski and Szlachetka (2017) for hollow truncated cone beams with rectilinear generatrice and generatrice shaped as parabola which is concave according to the beam axis, or Szlachetka, Jaworski and Chalecki (2017) - shaped as parabola which is convex according to the beam axis.

The purpose of this paper is to determine, using the Rayleigh's method, first natural frequency of transversal vibrations of bars (beams or posts) having a form of truncated cone and truncated wedge. It has been

凶olga_szlachetka@sggw.pl 
assumed that the vibration amplitude is small, material of the bars is homogeneous, isotropic and ideally elastic and their mass is distributed continuously. Assuming that the neutral bar axis deflected during vibrations has the same shape as the axis deflected by a static constant uniform continuous load, first natural frequencies are determined for truncated cone and truncated wedge beams for six supporting schemes: clamped pinned (CL-PN), clamped - sliding (CL-SL), clamped - clamped (CL-CL), clamped - free (CL-FR), pinned - sliding (PN-SL), pinned - pinned (PN-PN).

In the case of a truncated cone beam (Fig. 1), the diameter $\Delta(x)$ and second area moment $J(x)$ in any cross-section defined by a coordinate $x$ are equal to, respectively:

$$
\begin{gathered}
\Delta(x)=D-\frac{D-d}{L} x \\
J(x)=\frac{\pi \Delta^{4}(x)}{64}
\end{gathered}
$$

and a diameter quotient describing a convergence ratio of cone generatrices is defined as:

$$
\eta=\frac{D}{d}
$$

where: $D, d$-diameters of the beam at its ends;

$$
L \text { - beam length. }
$$

In the case of a truncated wedge beam vibrating in the $x-z$ plane (Fig. 1), wherein one face of the wedge has a constant width, whereas the height and second area moment in any cross-section defined by a coordinate $x$ are equal to, respectively:

$$
\begin{gathered}
\chi(x)=H-\frac{H-h}{L} x \\
J(x)=\frac{b \chi^{3}(x)}{12}
\end{gathered}
$$

and a height quotient, describing a convergence ratio of wedge walls, is defined as:

$$
\phi=\frac{H}{h}
$$

where: $H, h$ - heights of the beam at its ends;

$b$ - beam width;

$L$ - beam length.

\section{MATERIALS AND METHODS}

\section{Calculation of beam deflection}

The deflection of a truncated cone and wedge beam is calculated by quadruple integration of the differential equation of bar elastic deflection curve:

$$
\frac{d^{2}}{d x^{2}}\left(E J(x) \frac{d^{2} u(x)}{d x^{2}}\right)=q
$$

where: $u(x)$-deflection;

$E$ - longitudinal modulus of elasticity; $q-$ uniform continuous load. a

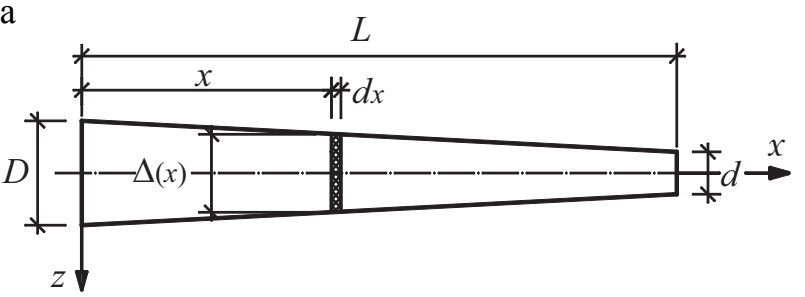

b

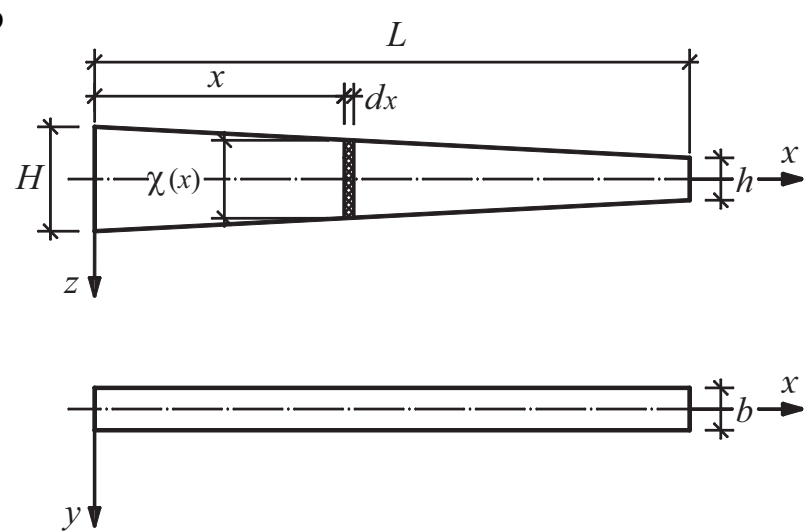

Fig. 1. Scheme of the beams under consideration: $a$ - truncated cone beam; $b$ - truncated wedge beam 
Bagdasaryan, V., Chalecki, M., Gierasimiuk, M., Jaworski, J. \& Szlachetka, O. (2018). First natural transverse frequency of truncated cone and wedge beams. Acta Sci. Pol. Architectura, 17 (1), 3-12. doi: 10.22630/ASPA.2018.17.1.1.

Boundary conditions are given in Table 1 and they depend on a supporting scheme under consideration.

Table 1. Supporting conditions

\begin{tabular}{cc}
\hline Supporting scheme & Boundary conditions \\
\hline CL-PN & $u(0)=\frac{d u}{d x}(0)=u(L)=\frac{d^{2} u}{d x^{2}}(L)=0$ \\
CL-SL & $u(0)=\frac{d u}{d x}(0)=\frac{d u}{d x}(L)=\frac{d^{3} u}{d x^{3}}(L)=0$ \\
CL-CL & $u(0)=\frac{d u}{d x}(0)=u(L)=\frac{d u}{d x}(L)=0$ \\
CL-FR & $u(0)=\frac{d u}{d x}(0)=\frac{d^{2} u}{d x^{2}}(L)=\frac{d^{3} u}{d x^{3}}(L)=0$ \\
PN-SL & $u(0)=\frac{d^{2} u}{d x^{2}}(0)=\frac{d u}{d x}(L)=\frac{d^{3} u}{d x^{3}}(L)=0$ \\
PN-PN & $u(0)=\frac{d^{2} u}{d x^{2}}(0)=u(L)=\frac{d^{2} u}{d x^{2}}(L)=0$
\end{tabular}

\section{Truncated cone}

The quadruple integration of equation (7) along with consideration of (2) and (3) gives:

$$
\begin{aligned}
u(x)= & C_{4}+C_{3} x+\frac{32 L^{4} \eta^{4}}{E \pi D^{4}(\eta-1)^{2}}\left(\frac { 1 } { 3 ( x + L \eta - x \eta ) ^ { 2 } } \left(C_{2}-\frac{3 x+2 L \eta-3 x \eta}{\eta-1} C_{1}+\right.\right. \\
& \left.\left.-\frac{L \eta(6 x+5 L \eta-6 x \eta)}{2(\eta-1)^{2}} q\right)-\frac{q}{(\eta-1)^{2}} \ln |x(\eta-1)-\eta L|\right)
\end{aligned}
$$

where integration constants $C_{1}, C_{2}, C_{3}, C_{4}$ must be determined from the boundary conditions (Table 1). For example, if a truncated cone beam is clamped in both ends, then the full equation of deflection has a form:

$$
\begin{aligned}
u(x)= & \frac{32 L^{3} \eta^{4} q}{E \pi D^{4}(\eta-1)^{3}}\left(-\frac{x(L-x)(L \eta-x-x \eta)}{(L \eta+x-x \eta)^{2}}+\frac{x^{2}(2 L \eta-2 x \eta+L)}{(\eta-1)(L \eta+x-x \eta)^{2}} \ln L+\right. \\
& \left.+\frac{\eta(L-x)^{2}(L \eta+2 x)}{(\eta-1)(L \eta+x-x \eta)^{2}} \ln L \eta-\frac{L}{(\eta-1)} \ln |x(\eta-1)-L \eta|\right)
\end{aligned}
$$


Assuming that the beam axis, deflected as a result of vibrations, has a shape described by equation (9), one can calculate the potential (elastic) energy in the maximally deflected position and the kinetic energy in the undeformed (neutral) position. The potential energy is equal to:

$$
E_{p}=\int_{0}^{L} \frac{1}{2} q u(x) d x
$$

If a mass of a material slice with the thickness $d x$ is denoted as $\mu(x)$, equal to:

$$
\begin{gathered}
\mu(x)=\frac{\rho \pi D^{2}(x)}{4} d x \quad \text { (11) } \begin{array}{l}
\text { simplification, the vibration period can be expressed as } \\
\text { a function of the material constants } E \text { and } \rho \text { as well as the } \\
\text { parameters } D, L, \eta \text {, determining the beam geometry: }
\end{array} \\
T=\frac{2 \pi}{\omega}=\frac{\pi L^{2} \eta}{D} \frac{2}{3} \sqrt{\frac{2}{15}} \sqrt{\frac{\rho}{E}} \sqrt{\frac{P_{1}(\eta)+P_{2}(\eta) \ln \eta+P_{3}(\eta)(\ln \eta)^{2}+P_{4}(\eta)(\ln \eta)^{3}}{P_{5}(\eta)+P_{6}(\eta) \ln \eta+P_{7}(\eta)(\ln \eta)^{2}}}
\end{gathered}
$$

then the kinetic energy of the beam is expressed as:

$$
\begin{aligned}
E_{k} & =\int_{0}^{L} \frac{1}{2} \omega^{2} u^{2}(x) \mu(x)= \\
& =\int_{0}^{L} \frac{1}{2} \omega^{2} u^{2}(x) \rho \frac{\pi D^{2}(x)}{4} d x
\end{aligned}
$$

where: $\omega$-vibration frequency;

$$
\rho \text { - mass density. }
$$

Comparison of the energies enables to determine the vibration frequency and period. After integration and

where:

$$
\begin{aligned}
P_{1}(\eta)= & -11-195 \eta+582 \eta^{2}-25770 \eta^{3}+75864 \eta^{4}-75864 \eta^{5}+25770 \eta^{6}-582 \eta^{7}+ \\
& +195 \eta^{8}+11 \eta^{9} \\
P_{2}(\eta)= & -174 \eta-1290 \eta^{2}-33966 \eta^{3}+35430 \eta^{4}+35430 \eta^{5}-33966 \eta^{6}-1290 \eta^{7}-174 \eta^{8} \\
P_{3}(\eta)= & -864 \eta^{2}-20520 \eta^{3}-11880 \eta^{4}+11880 \eta^{5}+20520 \eta^{6}+864 \eta^{7} \\
P_{4}(\eta)= & -4320 \eta^{3}-8640 \eta^{4}-8640 \eta^{5}-4320 \eta^{6} \\
P_{5}(\eta)= & -1+23 \eta-163 \eta^{2}+597 \eta^{3}-1338 \eta^{4}+1974 \eta^{5}-1974 \eta^{6}+1338 \eta^{7}-597 \eta^{8} \\
& +163 \eta^{9}-23 \eta^{10}+\eta^{11} \\
P_{6}(\eta)= & 12 \eta-84 \eta^{2}+240 \eta^{3}-336 \eta^{4}+168 \eta^{5}+168 \eta^{6}-336 \eta^{7}+240 \eta^{8}-84 \eta^{9}+12 \eta^{10} \\
P_{7}(\eta)= & 4 \eta-24 \eta^{2}+60 \eta^{3}-84 \eta^{4}+84 \eta^{5}-84 \eta^{6}+84 \eta^{7}-60 \eta^{8}+24 \eta^{9}-4 \eta^{10}
\end{aligned}
$$

The abovementioned formula has been derived with use of the MATHEMATICA environment and transformed to a form which enables to count vibration period using only a pocket calculator. Formulas for vibration periods for other supporting schemes can be presented in similar way. The appropriate formula for the CL-FR scheme can be found in the paper by Jaworski, Szlachetka and Aguilera-Cortés (2015).

\section{Truncated wedge}

The quadruple integration of equation (7) and consideration of (5) and (6) yields in a deflection formula for the truncated wedge beam, wherein integration constants $C_{1}, C_{2}, C_{3}, C_{4}$ must be determined according to the boundary conditions (Table 1): 


$$
\begin{aligned}
& u(x)=C_{4}+C_{3} x+\frac{6 L^{3} \phi^{3}}{E b H^{3}(\phi-1)^{2}}\left(\frac{1}{x+L \phi-x \phi} C_{2}+\frac{1}{\phi-1}\left(\frac{L \phi}{x+L \phi-x \phi}+2 \ln |x(\phi-1)-L \phi|\right) C_{1}+\right. \\
& \left.-\frac{1}{(\phi-1)^{2}}\left(\frac{2 x^{2}(\phi-1)^{2}-4 L x \phi(\phi-1)+L^{2} \phi^{2}}{2(x+L \phi-x \phi)}-(x+3 L \phi-x \phi) \ln |x(\phi-1)-L \phi|\right) q\right)
\end{aligned}
$$

For example, if a truncated wedge beam is clamped in both ends (CL-CL), then the full equation of deflection has a form:

$$
\begin{aligned}
u(x)= & \frac{6 L^{3} \phi^{3} q}{E b H^{3}(\phi-1)(2(\phi-1)+(\phi+1)(\ln L-\ln L \phi))}\left(\frac{x(L-x)}{x+L \phi-x \phi}+\frac{x \ln L}{\phi-1}+\right. \\
& +\frac{x^{2}(\ln L)^{2}}{(x+L \phi-x \phi)(\phi-1)^{2}}-\frac{\left(x^{2}+\phi^{2}(L-x)^{2}\right) \ln L \ln L \phi}{(x+L \phi-x \phi)(\phi-1)^{2}}+ \\
& +\frac{(L-x) \ln L \phi\left(x+L \phi-2 x \phi+\phi^{2}(L-x)(\ln L \phi-1)\right)}{(x+L \phi-x \phi)(\phi-1)^{2}}+ \\
& \left.+\frac{((L-2 x)(\phi-1)+(\ln L-\ln L \phi)(-x+L \phi-x \phi)) \ln |x(\phi-1)-L \phi|}{(\phi-1)^{2}}\right)
\end{aligned}
$$

The energy comparison and appropriate transformations yield in the formula for vibration period in a form:

$$
T=\frac{\pi L^{2} \phi}{3 H(\phi-1)^{2}} \sqrt{\frac{\rho}{E}} \sqrt{\frac{R_{1}(\phi)+R_{2}(\phi) \ln \phi+R_{3}(\phi)(\ln \phi)^{2}+R_{4}(\phi)(\ln \phi)^{3}+R_{5}(\phi) \ln (\ln \phi)^{5}}{R_{6}(\phi)+R_{7}(\phi) \ln \phi+R_{8}(\phi)(\ln \phi)^{2}+R_{9}(\phi)(\ln \phi)^{3}+R_{10}(\phi)(\ln \phi)^{4}}}
$$

where:

$$
\begin{aligned}
& R_{1}(\phi)=-212+1824 \phi-5176 \phi^{2}+5728 \phi^{3}-5728 \phi^{5}+5176 \phi^{6}-1824 \phi^{7}+212 \phi^{8} \\
& R_{2}(\phi)=-112+48 \phi+2672 \phi^{2}-9328 \phi^{3}+13440 \phi^{4}-9328 \phi^{5}+2672 \phi^{6}+48 \phi^{7}-112 \phi^{8} \\
& R_{3}(\phi)=-15-104 \phi-1234 \phi^{2}+2840 \phi^{3}-2840 \phi^{5}+1234 \phi^{6}+104 \phi^{7}+15 \phi^{8} \\
& R_{4}(\phi)=-276 \phi^{2}-2976 \phi^{3}+6504 \phi^{4}-2976 \phi^{5}-276 \phi^{6} \\
& R_{5}(\phi)=864 \phi^{4} \\
& R_{6}(\phi)=-8+32 \phi-40 \phi^{2}+40 \phi^{4}-32 \phi^{5}+8 \phi^{6} \\
& R_{7}(\phi)=-6-4 \phi+70 \phi^{2}-120 \phi^{3}+70 \phi^{4}-4 \phi^{5}-6 \phi^{6} \\
& R_{8}(\phi)=-1-8 \phi+19 \phi^{2}-19 \phi^{4}+8 \phi^{5}+\phi^{6} \\
& R_{9}(\phi)=8 \phi^{2}-16 \phi^{3}+8 \phi^{4} \\
& R_{10}(\phi)=4 \phi^{2}-4 \phi^{4}
\end{aligned}
$$




\section{COMPUTATIONAL EXAMPLES, VALIDATION OF RESULTS}

The periods for the first mode of free transversal vibrations of beams are presented in Figures 2-7. The beams have various static schemes and various convergence ratio of lateral faces what corresponds to vario- us values of diameters $d$ (for the truncated cone beam) or section heights $h$ (for the truncated wedge beam). The following data have been assumed: $E=205 \mathrm{GPa}$, $\rho=7850 \mathrm{~kg} \cdot \mathrm{m}^{-3}$, beam length $L=6 \mathrm{~m}$; for the truncated cone $D=0.2 \mathrm{~m}$ and for the truncated wedge $H=0.2 \mathrm{~m}, b=0.1 \mathrm{~m}$. Results of these calculations are compared to those obtained with use of FEM.

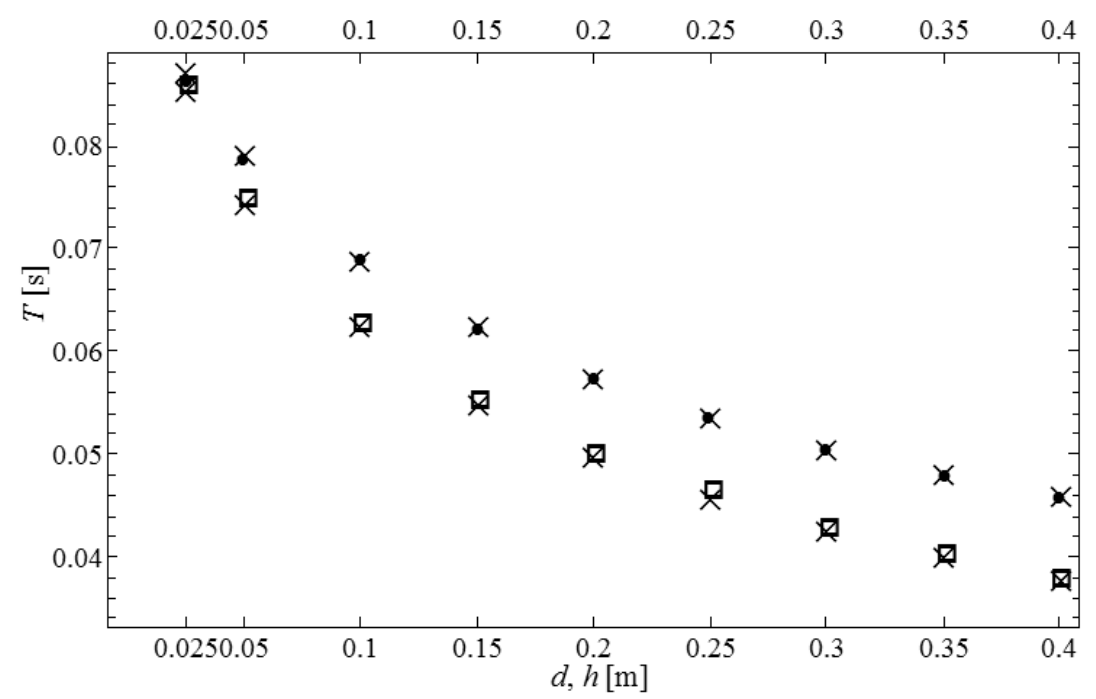

Fig. 2. Comparison of free vibration periods $T$ for truncated cone beams (dots) and truncated wedge beams (squares) to the results of FEM (crosses) for the clamped-pinned supporting scheme (CL-PN)

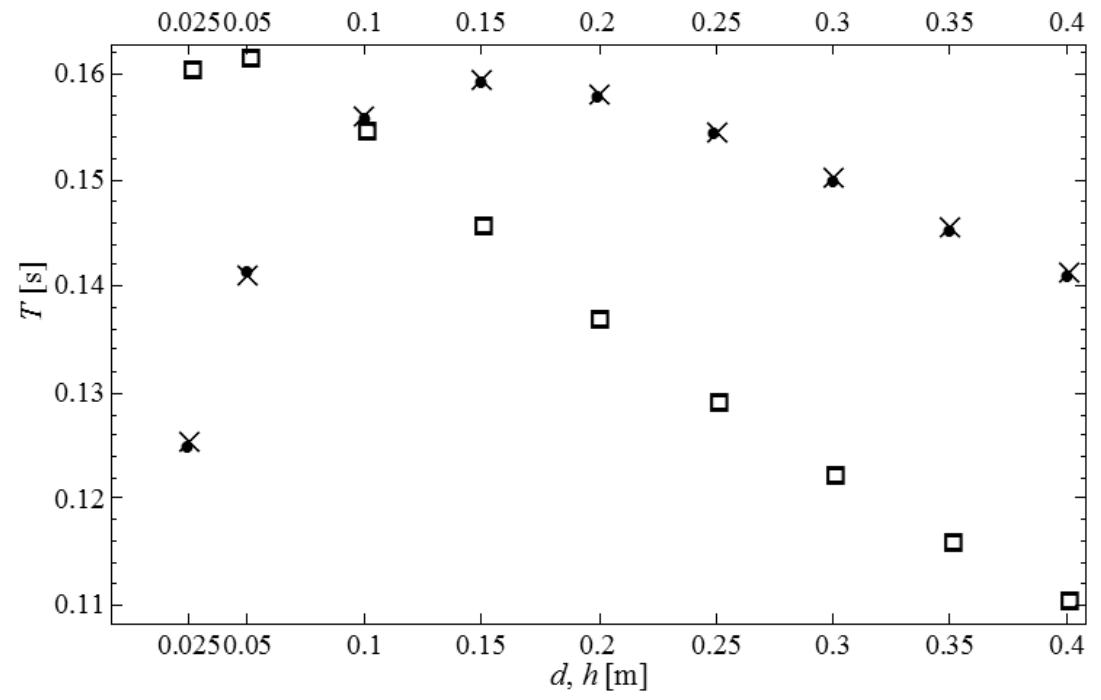

Fig. 3. Comparison of free vibration periods $T$ for truncated cone beams (dots) and truncated wedge beams (squares) to the results of FEM (crosses) for the clamped-sliding supporting scheme (CL-SL) 


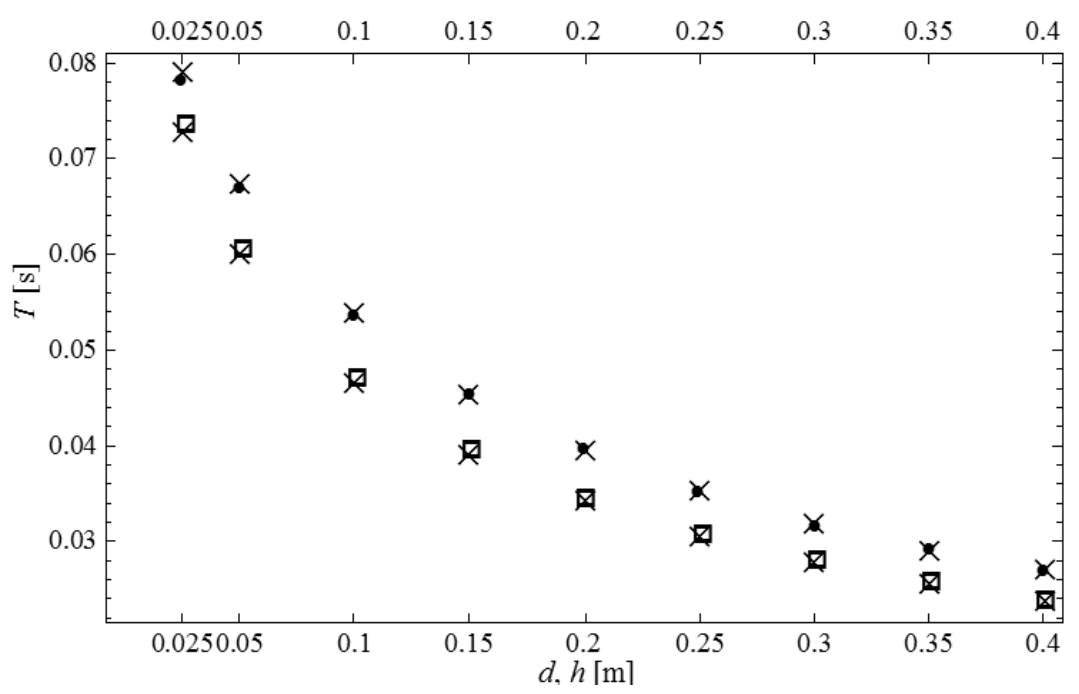

Fig. 4. Comparison of free vibration periods $T$ for truncated cone beams (dots) and truncated wedge beams (squares) to the results of FEM (crosses) for the clamped-clamped supporting scheme (CL-CL)

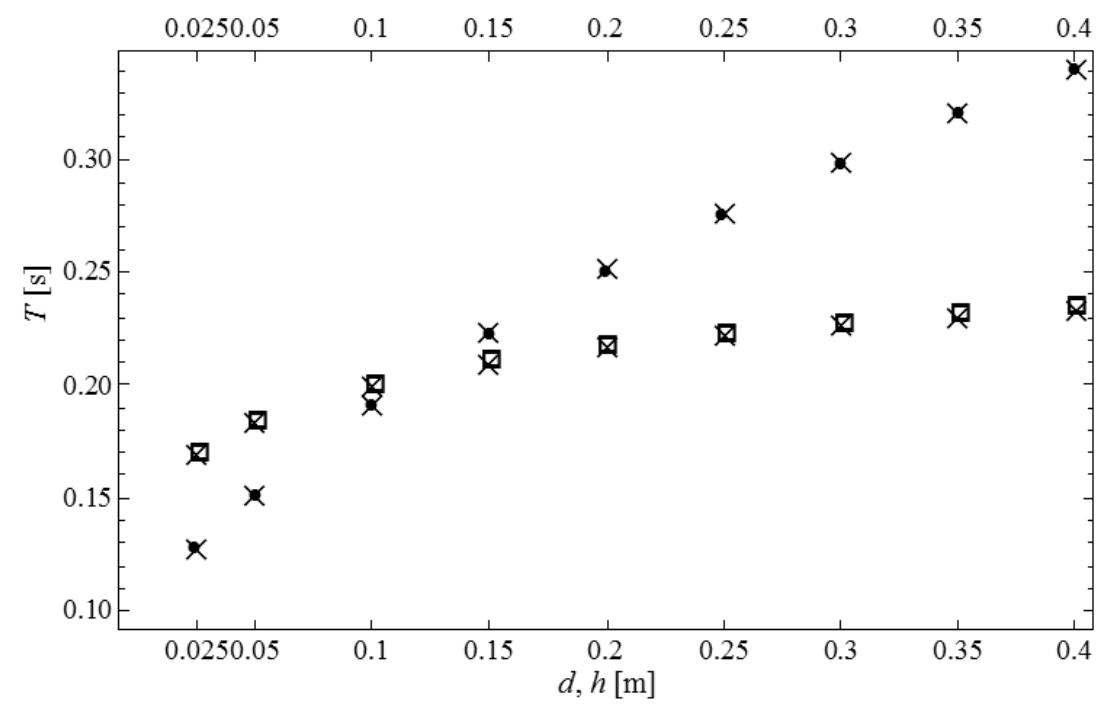

Fig. 5. Comparison of free vibration periods $T$ for truncated cone beams (dots) and truncated wedge beams (squares) to the results of FEM (crosses) for the clamped-free supporting scheme (CL-FR)

The results obtained in this study are concordant with those achieved from calculations performed with use of FEM in the Autodesk Fusion 360 program. The highest differences between the results from both methods in the investigated range do not exceed $1.4 \%$ for the truncated cone and $1.3 \%$ for the truncated wedge. The average difference between the results from both methods is equal to $0.4 \%$.
The results obtained in this study from the calculations for beams characterized by the convergence of lateral faces from 1 to 10 are compared to the results of a benchmark solution for free vibrations of Euler-Bernoulli beam, given by Naguleswaran (1994). The comparison is contained in Table 2 (truncated cone beam) and Table 3 (truncated wedge beam); a dimensionless frequency parameter $\Omega$, presented in 


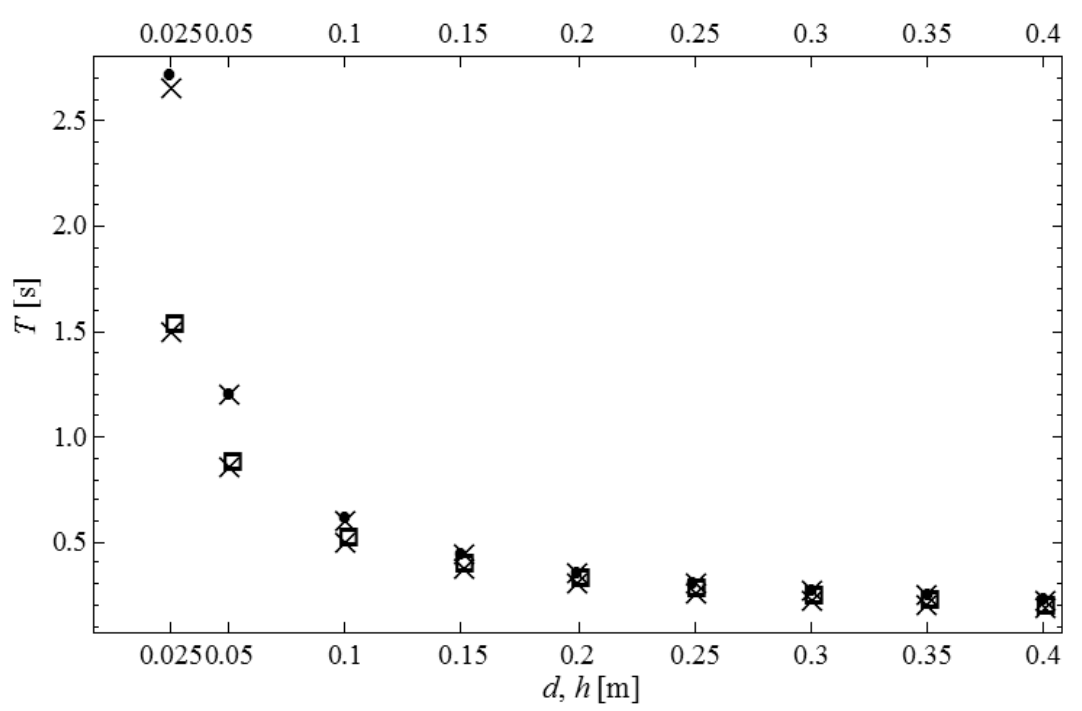

Fig. 6. Comparison of free vibration periods $T$ for truncated cone beams (dots) and truncated wedge beams (squares) to the results of FEM (crosses) for the pinned-sliding supporting scheme (PN-SL)

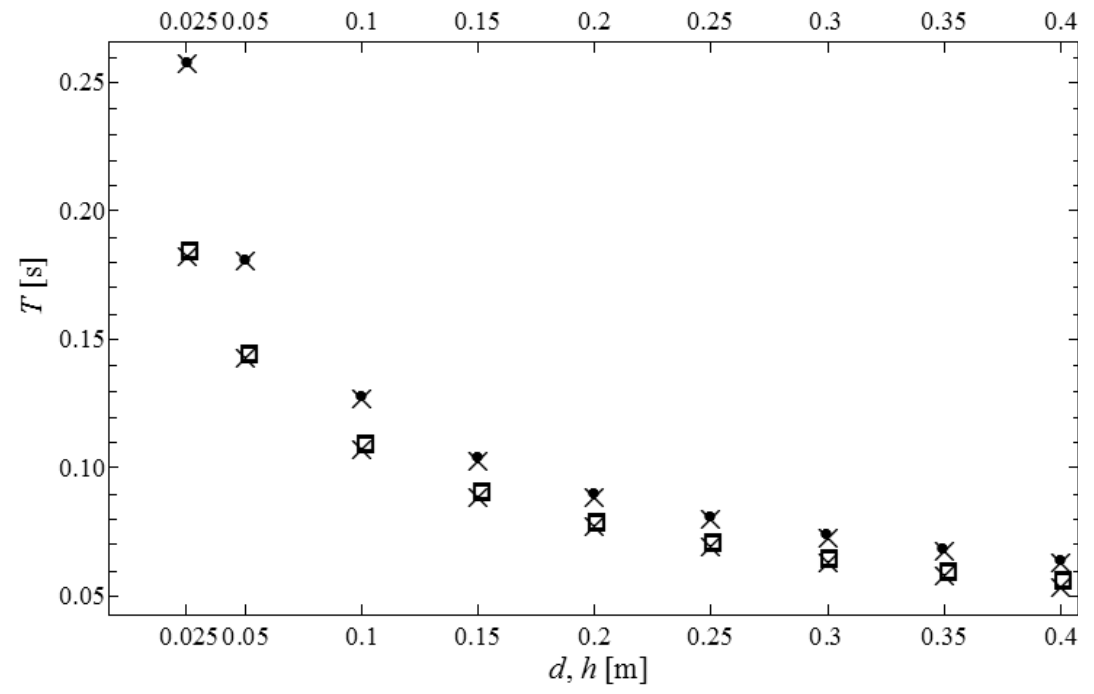

Fig. 7. Comparison of free vibration periods $T$ for truncated cone beams (dots) and truncated wedge beams (squares) to the results of FEM (crosses) for the pinned-pinned supporting scheme (PN-PN)

these tables, is described by:

$$
\Omega=2 \pi \frac{L^{2}}{T} \sqrt{\frac{A_{0}}{J_{0}}} \sqrt{\frac{\rho}{E}}
$$

where $A_{0}$ and $J_{0}$ are, respectively, cross-section area and second area moment for $x=0$.
The parameter $\Omega$ calculated by the authors is slightly higher than the values given by Naguleswaran (1994). The relative error $\delta$ does not exceed $1.7 \%$ for the truncated cone and $0.5 \%$ for the truncated wedge and the difference does not exceed $0.3 \%$ in average. The highest differences occur for high (equal to 10) convergence of lateral faces. 
Table 2. Comparison of the authors' results (A) to the benchmark solution $(\mathrm{N})$ for truncated cone beam

\begin{tabular}{|c|c|c|c|c|c|c|c|c|c|}
\hline$d[\mathrm{~cm}]$ & & 2 & 4 & 6 & 8 & 10 & 12 & 14 & 20 \\
\hline$\eta[-]$ & & 10 & 5 & $10 / 3$ & 2.5 & 2 & $5 / 3$ & $10 / 7$ & 1 \\
\hline \multirow{3}{*}{ CL-CL } & $\Omega \mathrm{A}$ & 10.9433 & 12.5014 & 13.9292 & 15.2717 & 16.5542 & 17.7917 & 18.9867 & 22.4507 \\
\hline & $\Omega \mathrm{N}$ & 10.7636 & 12.3820 & 13.8345 & 15.1898 & 16.4790 & 17.7199 & 18.9232 & 22.3731 \\
\hline & $\delta[\%]$ & 1.67 & 0.96 & 0.68 & 0.54 & 0.46 & 0.41 & 0.34 & 0.35 \\
\hline \multirow{3}{*}{ CL-PN } & $\Omega \mathrm{A}$ & 10.0692 & 10.8836 & 11.6115 & 12.2725 & 12.8826 & 13.4525 & 13.9898 & 15.4516 \\
\hline & $\Omega \mathrm{N}$ & 9.9086 & 10.7987 & 11.5569 & 12.2328 & 12.8505 & 13.4238 & 13.9617 & 15.4213 \\
\hline & $\delta[\%]$ & 1.62 & 0.79 & 0.47 & 0.32 & 0.25 & 0.21 & 0.20 & 0.20 \\
\hline \multirow{3}{*}{ CL-SL } & $\Omega \mathrm{A}$ & 7.3699 & 6.5248 & 6.0818 & 5.8282 & 5.6817 & 5.6019 & 5.5666 & 5.6127 \\
\hline & $\Omega \mathrm{N}$ & 7.2980 & 6.5159 & 6.0781 & 5.8223 & 5.6728 & 5.5904 & 5.5527 & 5.5932 \\
\hline & $\delta[\%]$ & 0.99 & 0.14 & 0.06 & 0.10 & 0.16 & 0.21 & 0.25 & 0.35 \\
\hline \multirow{3}{*}{ CL-FR } & $\Omega \mathrm{A}$ & 7.2794 & 6.2032 & 5.5134 & 5.0170 & 4.6364 & 4.3320 & 4.0812 & 3.5302 \\
\hline & $\Omega \mathrm{N}$ & 7.2049 & 6.1964 & 5.5093 & 5.0090 & 4.6252 & 4.3188 & 4.0669 & 3.5156 \\
\hline & $\delta[\%]$ & 1.03 & 0.11 & 0.07 & 0.16 & 0.24 & 0.31 & 0.35 & 0.42 \\
\hline \multirow{3}{*}{ PN-SL } & $\Omega \mathrm{A}$ & 0.2450 & 0.5728 & 0.8875 & 1.1752 & 1.4367 & 1.6756 & 1.8955 & 2.4693 \\
\hline & $\Omega \mathrm{N}$ & 0.2450 & 0.5727 & 0.8874 & 1.1752 & 1.4367 & 1.6754 & 1.8951 & 2.4675 \\
\hline & $\delta[\%]$ & 0.012 & 0.016 & 0.009 & 0.002 & 0.003 & 0.014 & 0.023 & 0.071 \\
\hline \multirow{3}{*}{ PN-PN } & $\Omega \mathrm{A}$ & 3.0720 & 4.3763 & 5.3800 & 6.2261 & 6.9707 & 7.6426 & 8.2594 & 9.8811 \\
\hline & $\Omega \mathrm{N}$ & 3.0512 & 4.3527 & 5.3589 & 6.2086 & 6.9566 & 7.6314 & 8.2502 & 9.8695 \\
\hline & $\delta[\%]$ & 0.54 & 0.39 & 0.28 & 0.20 & 0.15 & 0.11 & 0.54 & 0.12 \\
\hline
\end{tabular}

Table 3. Comparison of the authors' results (A) to the benchmark solution $(N)$ for truncated wedge beam

\begin{tabular}{|c|c|c|c|c|c|c|c|c|c|}
\hline$h[\mathrm{~cm}]$ & & 2 & 4 & 6 & 8 & 10 & 12 & 14 & 20 \\
\hline$\Phi[-]$ & & 10 & 5 & $10 / 3$ & 2.5 & 2 & $5 / 3$ & $10 / 7$ & 1 \\
\hline \multirow{3}{*}{ CL-CL } & $\Omega \mathrm{A}$ & 9.9333 & 11.8915 & 13.5356 & 15.0171 & 16.3945 & 17.6980 & 18.9469 & 22.4508 \\
\hline & $\Omega \mathrm{N}$ & 9.8846 & 11.8417 & 13.4832 & 14.9616 & 16.3356 & 17.6354 & 18.8791 & 22.373 \\
\hline & $\delta[\%]$ & 0.49 & 0.42 & 0.39 & 0.37 & 0.36 & 0.35 & 0.36 & 0.35 \\
\hline \multirow{3}{*}{ CL-PN } & $\Omega \mathrm{A}$ & 8.6635 & 9.8273 & 10.7633 & 11.5822 & 12.3265 & 13.0178 & 13.6696 & 15.4517 \\
\hline & $\Omega \mathrm{N}$ & 8.6301 & 9.7995 & 10.7372 & 11.5564 & 12.3001 & 12.9903 & 13.64 & 15.4213 \\
\hline & $\delta[\%]$ & 0.39 & 0.28 & 0.24 & 0.22 & 0.21 & 0.21 & 0.22 & 0.20 \\
\hline \multirow{3}{*}{ CL-SL } & $\Omega$ A & 4.8325 & 4.7540 & 4.7873 & 4.8675 & 4.9715 & 5.0888 & 5.2142 & 5.6127 \\
\hline & $\Omega \mathrm{N}$ & 4.8274 & 4.7459 & 4.7766 & 4.8548 & 4.9573 & 5.0733 & 5.1976 & 5.5933 \\
\hline & $\delta[\%]$ & 0.11 & 0.17 & 0.22 & 0.26 & 0.29 & 0.31 & 0.32 & 0.35 \\
\hline \multirow{3}{*}{ CL-FR } & $\Omega \mathrm{A}$ & 4.6360 & 4.3023 & 4.0947 & 3.9488 & 3.8389 & 3.7524 & 3.6820 & 3.5302 \\
\hline & $\Omega \mathrm{N}$ & 4.6307 & 4.2925 & 4.0817 & 3.9343 & 3.8238 & 3.7371 & 3.6667 & 3.51557 \\
\hline & $\delta[\%]$ & 0.12 & 0.23 & 0.32 & 0.37 & 0.40 & 0.41 & 0.42 & 0.42 \\
\hline \multirow{3}{*}{ PN-SL } & $\Omega$ A & 0.4170 & 0.7451 & 1.0252 & 1.2749 & 1.5036 & 1.7167 & 1.9177 & 2.4693 \\
\hline & $\Omega \mathrm{N}$ & 0.4170 & 0.745 & 1.0251 & 1.2748 & 1.5033 & 1.7162 & 1.9169 & 2.4674 \\
\hline & $\delta[\%]$ & 0.005 & 0.010 & 0.006 & 0.009 & 0.020 & 0.029 & 0.043 & 0.076 \\
\hline \multirow{3}{*}{ PN-PN } & $\Omega$ A & 3.8999 & 4.9294 & 5.7541 & 6.4745 & 7.1289 & 7.7365 & 8.3088 & 9.8770 \\
\hline & $\Omega \mathrm{N}$ & 3.8895 & 4.9148 & 5.7454 & 6.4666 & 7.1215 & 7.7295 & 8.3019 & 9.8695 \\
\hline & $\delta[\%]$ & 0.27 & 0.30 & 0.15 & 0.12 & 0.10 & 0.09 & 0.08 & 0.08 \\
\hline
\end{tabular}




\section{CONCLUSIONS}

The Rayleigh's method can be successfully applied for calculations of the first natural frequency of transverse vibrations of non-prismatic bars. Comparison between the results obtained by the authors and the results of the benchmark solutions for Euler-Bernoulli's truncated cone and wedge beams or the FEM results shows that the accuracy of the presented method is sufficient for practical engineering calculations.

For many cases - what has been shown for the CL-CL truncated cone and wedge beams - frequency (or period) formulas obtained using the Rayleigh's method with assumption that the bar axis deflected during vibrations has a shape of a beam deflected by a static constant uniform continuous load, can be presented in so simple form that a pocket calculator is sufficient for calculations.

\section{REFERENCES}

Caruntu, D. I. (2009). Dynamic modal characteristics of transverse vibrations of cantilevers of parabolic thickness. Mechanics Research Communications, 36 (3), 391-404.

Conway, H. D. \& Dubil, J. F. (1965). Vibration Frequencies of Truncated-Cone and Wedge Beams. Journal of Applied Mechanics (ASME), 32 (4), 932-934.

Datta, A. K. \& Sil, S. N. (1996). An analysis of free undamped vibration of beams of varying cross-section. Computers \& Structures, 59 (3), 479-483.

Ece, M. C., Aydogdu, M. \& Taskin, V. (2007). Vibration of variable cross-section beam. Mechanics Research Communications, 34, 78-84.
Jaworski, J. \& Szlachetka, O. (2017). Free Vibrations of Cantilever Bars with Linear and Nonlinear Variable Cross-Section. Discontinuity, Nonlinearity, and Complexity, 6 (4), 489-501.

Jaworski, J., Szlachetka, O. \& Aguilera-Cortés, L. A. (2015). Application of Rayleigh's method to calculation of the first natural frequency of cantilever columns with variable cross-section (in Polish). Journal of Civil Engineering, Environment and Architecture, XXXII, 185-194.

Laura, P. A. A., Gutierrez, R. H. \& Rossi, R. E. (1996). Free Vibrations of beams with bilinearly varying thickness. Journal of Ocean Engineering, 23 (1), 1-6.

Naguleswaran, S. (1994). A direct solution for the transverse vibration of Euler-Bernoulli wedge and cone beams. Journal of Sound and Vibration, 172 (3), 289-304.

Szlachetka, O., Jaworski, J. \& Chalecki, M. (2017). Analysis of free vibrations of cantilever bars with parabolically variable cross-sections using the Rayleigh's method. Acta Scientiarum Polonorum Architectura, 16 (4), 5-14.

Torabi, K., Afshari, H. \& Najafi, H. (2013). Vibration Analysis of Multi-Step Bernoulli-Euler and Timoshenko Beams Carrying Concentrated Masses. Journal of Solid Mechanics, 5 (4), 336-349.

Wang, D. (2012). Frequency sensitivity analysis for beams carrying lumped masses with translational and rotary inertias. International Journal of Mechanical Sciences, 65, 192-202.

Wu, J. S. \& Chiang, L. K. (2004). Free vibrations of solid and hollow wedge beams with rectangular or circular cross-sections and carrying any number of point masses. International Journal for Numerical Methods in Engineering, 60 (3), 695-718.

Zhou, D. \& Cheung, Y. K. (2000). The free vibration of a type of tapered beams. Computer Methods in Applied Mechanics and Engineering, 188 (1), 203-216.

\section{PIERWSZA CZĘSTOŚĆ DRGAŃ WLASNYCH BELEK W KSZTAtCIE ŚCIĘTEGO STOŻKA I KLINA}

\section{STRESZCZENIE}

Metodą Rayleigha wyznaczono częstość i okres odpowiadający pierwszej postaci drgań własnych (giętnych) belek o zmiennym przekroju poprzecznym, w kształcie ściętego stożka i ściętego klina. Uwzględniono sześć schematów podparcia. Przyjęto, że belki sa wykonane z materiału jednorodnego i sprężystego, i że kształt wychylenia osi belki podczas drgań odpowiada ugięciu statycznemu pod działaniem stałego obciążenia ciągłego. Otrzymane częstości drgań porównano z rezultatami uzyskanymi metodą elementów skończonych oraz z podanymi w literaturze wzorcowymi wynikami dla drgań własnych belki Bernoulliego-Eulera. Stwierdzono dużą zgodność wyników, wystarczającą do obliczeń inżynierskich.

Słowa kluczowe: ścięty stożek, ścięty klin, belka, pierwsza częstość drgań własnych, metoda Rayleigha 